\title{
Ulinastatin Exhibits Antinociception in Rat Models of Acute Somatic and Visceral Pain Through Inhibiting the Local and Central Inflammation
}

\author{
Mei-Xiang Zhan ${ }^{1,2, *}$ \\ Li Tang ${ }^{3, *}$ \\ Yun-Fei $\mathrm{Lu}^{4, *}$ \\ Huang-Hui $\mathrm{Wu}^{1}{ }^{1} *$ \\ Zhi-Bin Guo' \\ Zhong-Mou Shi' \\ Chen-Long Yang' \\ Yi-Qing Zou ${ }^{1,2}$ \\ Fei Yang ${ }^{1,2,5}$ \\ Guo-Zhong Chen ${ }^{1,2}$
}

'Department of Anesthesiology and Perioperative Medicine, Clinical Medical College, (900 Hospital of the Joint Logistic Support Force), Fujian Medical University, Fuzhou, Fujian, 350025, People's Republic of China; ${ }^{2}$ Department of Anesthesiology and Perioperative Medicine, Dongfang Hospital, Xiamen University, Fuzhou, Fujian, 350025, People's Republic of China; ${ }^{3}$ Department of Stomatology, Beijing Friendship Hospital, Capital Medical University, Beijing, 100050, People's Republic of China; ${ }^{4}$ Department of Anesthesiology, Fifth Medical Center of Chinese PLA General Hospital, Beijing, I00039, People's Republic of China; ${ }^{5}$ Laboratory of Pain Research, School of Basic Medical Sciences, Fujian Medical University, Fuzhou, Fujian, 350I22, People's Republic of China

*These authors contributed equally to this work

Correspondence: Guo-Zhong Chen; Fei Yang

Department of Anesthesiology and Perioperative Medicine, 900 Hospital of the Joint Logistic Support Force, Fujian Medical University, \#156 West $2^{\text {nd }}$ Ring Road North, Gulou District, Fuzhou, 350025, People's Republic of China Email cgzssq2000@sina.com; yangfeimedbrain@outlook.com
Introduction: Ulinastatin, a broad-spectrum serine protease inhibitor, has been widely used to treat various diseases clinically. However, so far, the antinociceptive effect of ulinastatin remains less studied experimentally and the underlying mechanisms of ulinastatin for pain relief remain unclear. This study aimed to find evidence of the analgesic effect of ulinastatin on acute somatic and visceral pain.

Methods: The analgesic effect of ulinastatin on acute somatic and visceral pain was evaluated by using formalin and acetic acid-induced writhing test. The analgesic mechanism of ulinastatin was verified by detecting the peripheral inflammatory cell infiltration and spinal glial activation with hematoxylin-eosin (H\&E) and immunohistochemistry staining.

Results: We found that both of intraperitoneal (i.p.) pre-administration and postadministration of ulinastatin could reduce the total number of flinching and the licking duration following intraplantar formalin injection in a dose-related manner. However, the inhibitory effect of ulinastatin existed only in the second phase (Phase 2) of formalin-induced spontaneous pain response, with no effect in the first phase (Phase 1). The formalin-induced edema and ulcer were also improved by i.p. administration of ulinastatin. Moreover, i.p. administration of ulinastatin was also able to delay the occurrence of acetic acid-induced writhing and reduced the total number of writhes dose-dependently. We further demonstrated that ulinastatin significantly decreased the local inflammatory cell infiltration in injured paw and peritoneum tissue under formalin and acetic acid test separately. The microglial and astrocytic activation in the spinal dorsal horn induced by intraplantar formalin and i.p. acetic acid injection were also dramatically inhibited by i.p. administration of ulinastatin.

Conclusion: Our results for the first time provided a new line of evidence showing that ulinastatin could attenuate acute somatic and visceral pain by inhibiting the peripheral and spinal inflammatory reaction.

Keywords: Ulinastatin, formalin, somatic pain, visceral pain, inflammation, antinociception

\section{Introduction}

Pain is an enormous global health problem and once became the greatest cause of global burden of disease. Epidemiology data suggest that about $20 \%$ of adults are suffering from pain and nearly $10 \%$ are newly diagnosed with chronic pain each year. ${ }^{1}$ Nevertheless, the pain management is still a huge medical challenge because of the unique nature of each sufferer and may be further complicated by the different anatomical region, etiology, intensity and pathophysiology. So far, there is no single treatment or approach that is going to be of benefit for all types of pain or 
all people. Nowadays, nonsteroidal anti-inflammatory drugs (NSAIDs) and opioids remain the frequently used treatment for moderate to severe acute pain., ${ }^{2,3}$ However, their analgesic efficacy are still less satisfactory and their usage is accompanied by various side effects such as gastro-intestinal intolerance, organ impairment, opioid tolerance and misuse as well as opioid-induced hyperalgesia. ${ }^{4-6}$ Thus, it is urgent to investigate the underlying mechanisms of pain and to explore new effective strategies against pain.

In recent years, serine proteases and their corresponding $G$ protein-coupled receptors, proteinase-activated receptors (PARs), are considered to play a critical role in the modulation of inflammation and pain. ${ }^{7}$ Administration of endogenous serine proteases into peripheral tissues produced significant neurogenic inflammation, nocifensive behaviors and spinal Fos up-regulation in a PAR2dependent manner. ${ }^{8,9}$ Colonic administration of trypsinrelated serine proteases could induce significant inflammatory reaction and cause significant somatic and visceral hyperalgesia and allodynia which were inhibited by serine protease inhibitors and a PAR2 antagonist. ${ }^{10-12} \mathrm{~A}$ recent study demonstrated that SerpinA3N, a serine protease inhibitor derived from dorsal root ganglion (DRG) neurons, could attenuate neuropathic pain by inhibiting T cellderived leukocyte elastase. ${ }^{13}$ As a broad-spectrum serine protease inhibitor, the analgesic potential of ulinastatin is gradually being uncovered. In vincristine-induced neuropathic pain, ulinastatin exhibited synergistic analgesic effect when combined with dexmedetomidine. ${ }^{14}$ By downregulating P2Y2 receptor and AMPK expression in the spinal dorsal horn, ulinastatin was effective to prevent the development of mechanical allodynia and thermal hypersensitivity in the rat sciatic nerve ligation model. ${ }^{15}$ Likewise, ulinastatin also attenuated pain behavior via inhibition of the calcineurin-mediated inflammatory response in dorsal root ganglion (DRG) induced by lumbar 5 ventral root transection. ${ }^{16}$ However, so far, the research on the analgesic effect of ulinastatin is still insufficient and the underlying mechanisms of ulinastatin for pain relief remain unclear.

In the present study, we used two classical pain model, formalin and acetic acid-induced writhing test, to evaluate the anti-nociception effect of ulinastatin on acute somatic and visceral pain. In addition, the anti-inflammatory activities of ulinastatin in peripheral and central were addressed to further understand the mechanisms of ulinastatin.

\section{Materials and Methods}

\section{Animals}

Experiments were performed on male Sprague-Dawley rats (200-250 g, provided by Laboratory Animal Center of 900 Hospital). The animals were housed in plastic cage under specific pathogen-free conditions with a $12 \mathrm{~h}$ light/ dark cycle and with free access to water and food. This study was carried out in accordance with the recommendations of the Animal Care and Use Committee of 900 Hospital of the Joint Logistic Support Force (Authorization No.: 2020-063) and performed in accordance with the National Institutes of Health Guidelines for the Care and Use of Laboratory Animals. The number of rats used and their suffering were minimized. Total number of 96 rats were used in the present study. During the whole experiment, the rats were randomized.

\section{Formalin Test}

The acute somatic pain was induced by intraplantar formalin injection as previous studies, which consisted of administering $100 \mu \mathrm{L}$ of $5 \%$ formalin in the subplantar region of the right hind paw. Before formalin injection, each rat was acclimated to the testing chamber for at least $30 \mathrm{~min}$ individually. Immediately after the formalin injection, the rats were returned to the testing chamber and spontaneous pain behaviors were observed for $60 \mathrm{~min}$. The number of flinching (an elevation and shrinking back of the injected paw) and the duration of spontaneous licking of the injected hindpaw were recorded during 5 min intervals. The first 10 min post formalin injection is known as the first phase (phase 1) and the period between 15-60 min as the second phase (phase 2). For evaluating the preventive effect of ulinastatin on formalin-induced acute somatic pain, ulinastatin $(2000,10,000$ and 50,000 $\mathrm{U} / \mathrm{kg}$ ) or saline were i.p. administered $10 \mathrm{~min}$ prior to formalin injection. For evaluating the therapeutic effect of ulinastatin on formalin-induced acute somatic pain, ulinastatin $(50,000 \mathrm{U} / \mathrm{kg})$ or saline were i.p. administered 5 min post formalin injection.

\section{Acetic Acid-Induced Writhing}

The acute visceral pain was induced by i.p. acetic acid injection refer to previous studies, ${ }^{17}$ which consisted of administering $10 \mathrm{~mL} / \mathrm{kg}$ of $0.6 \%$ acetic acid into the abdominal cavity of animals. Before acetic acid injection, all rats were acclimatized to testing chamber for at least 30 min individually. Immediately after injection, the rats were 
returned to the testing chamber and spontaneous pain behaviors were observed for $60 \mathrm{~min}$. The number of abdominal writhing episodes (contraction of the abdominal area with elongation of hind legs) were recorded for 60 min starting from 5 min after acetic acid injection and the latency from acetic acid injection to the first writhing were also recoded in each rat. In the present study, we performed acetic acid-induced writhing assay to evaluate the effect of ulinastatin on visceral pain because this assay has been widely used to determine the degree of antinociception of opioids and NSAIDs, and it has been suggested as a screening tool for assessing the analgesic or anti-inflammatory agents. ${ }^{18-21}$ For evaluating the preventive effect of ulinastatin on acetic acid-induced acute visceral pain, ulinastatin $(2000,10,000$ and $50,000 \mathrm{U} / \mathrm{kg})$ or saline were i.p. administered $10 \mathrm{~min}$ prior to acetic acid injection. For evaluating the therapeutic effect of ulinastatin on acetic acid-induced acute visceral pain, ulinastatin $(50,000 \mathrm{U} / \mathrm{kg})$ or saline were i.p. administered $5 \mathrm{~min}$ post acetic acid injection.

\section{Measurements of Paw Edema}

Formalin-induced paw edema was calculated by measuring the foot thickness in the dorsal-plantar axis with a caliper. According to previous studies, the magnitude of paw edema was calculated as the mean difference of paw thickness (paw thickness of injected side-paw thickness of contralateral side)/paw thickness of contralateral side. $^{22,23}$ In addition, formalin injection also produced ulcers on the plantar surface of the injected paw characterized as tissue damage, inflammatory exudation and scab. ${ }^{23}$ In the present study, the incidence of ulcers in formalininjected paw and percentage of ulcer healing were also determined by one analyst blinded to the experimental treatments.

\section{Hematoxylin-Eosin (H\&E) Staining}

After the rats were sacrificed, tissues from the plantar skin or peritoneum were harvested, rinsed, fixed in $4 \%$ paraformaldehyde overnight, dehydrated and embedded in paraffin. Next, the tissues were sliced and subjected to standard HE staining, and the sections were imaged using an Olympus BX51 microscope for evaluating the inflammation infiltration. Three samples were selected from each group, and two regions were selected from each sample, which were observed blindly by three independent observers. Based on previous studies, ${ }^{24}$ inflammation infiltration was analysed by four-grade semi quantitative scoring: 0 , no inflammation, 1 , weak, 2 , moderate, 3 , strong.

\section{Immunohistochemistry Staining}

Rats were deeply anesthetized with pentobarbital (100 mg/ $\mathrm{kg}$, i.p.) and perfused via cardiac puncture initially with 0.1 M PBS ( $\mathrm{pH} 7.4$ ) and subsequently with 4\% paraformaldehyde in $0.1 \mathrm{M}$ PBS. The lumbar spinal cord segment was quickly removed and soaked in the $4 \%$ poly formaldehyde overnight at $4^{\circ} \mathrm{C}$. After tissue dehydration/rehydration, spinal cord segments were paraffin embedded. The lumbar enlargement region was sectioned into slices $5 \mu \mathrm{m}$ in thickness by microtome. Immunohistochemistry staining for Iba-1 or GFAP was performed with an avidinbiotin-peroxidase complex (ABC) method. In detail, the sections were deparaffinized in xylene and hydrated through a graded series of ethanol. Endogenous peroxidase was inhibited with $3 \% \mathrm{H}_{2} \mathrm{O}_{2}$ in $100 \%$ methanol for 20 min. Antigen retrieval was carried out by microwaving in $10 \mathrm{mM}$ citrate buffer $(\mathrm{pH}=6)$ for $10-30 \mathrm{~min}$ to activate the antigens. After being rinsed in PBS, the sections were incubated with normal goat serum for $1 \mathrm{~h}$ at room temperature and then incubated overnight at $4^{\circ} \mathrm{C}$ in humid chambers with the primary antibody (anti-GFAP, 1:1000, rabbit, Abcam; anti-Iba1, 1:2000, rabbit, Abcam). After that, the sections were washed and then incubated with biotinylated anti-rabbit secondary antibody (1:500; AP182B; Millipore) diluted in PBS for $3 \mathrm{~h}$, and sections were finally incubated in a solution containing 0.05 $\mathrm{M}$ Tris- $\mathrm{HCl}, 0.13 \%$ diaminobenzidine, and $0.005 \%$ hydrogen peroxide for 20 to $30 \mathrm{~min}$ in order to complete the diaminobenzidine reaction. After dehydration in graded alcohol and xylene, the sections were coverslipped with Permount mounting medium. Slides were examined with light microscope (Labomed, USA) and images were captured. The density of GFAP and Ibal immunostaining was assessed quantitatively by a blinded experimenter with Image $\mathrm{J}$ software.

\section{Experimental Design}

The experimental procedure is shown in Figure 1. After arriving, the rats were allowed to acclimate to the experimental environment for 5 days before test. For evaluating the effect of UTI on the acute somatic pain, UTI was either intraperitoneal administrated $10 \mathrm{~min}$ before or $5 \mathrm{~min}$ after formalin intraplantar injection. Behavior test (flinching and licking) was performed during the $1 \mathrm{~h}$ immediately after formalin injection. Evaluation of paw edema and ulcer was 


\section{A Effect of UTI on formalin-induced somatic pain}

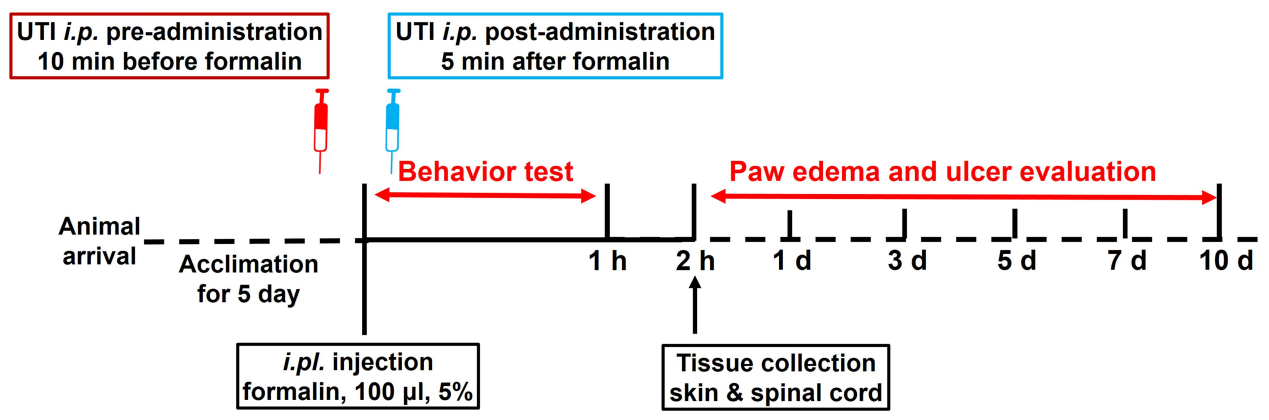

\section{B Effect of UTI on acetic acid-induced visceral pain}

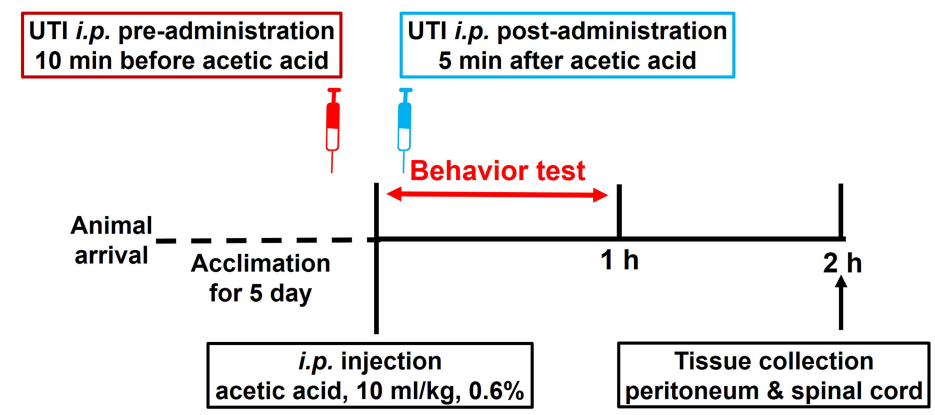

Figure I Experimental design and timeline. (A) Schematic diagram for exploring the effect of UTI on formalin-induced somatic pain. (B) Schematic diagram for exploring the effect of UTI on acetic acid-induced visceral pain. i.p. intraperitoneal; i.pl. intraplantar; UTI, ulinastatin.

conducted at $2 \mathrm{~h}, 1 \mathrm{~d}, 3 \mathrm{~d}, 5 \mathrm{~d}, 7 \mathrm{~d}$ and $10 \mathrm{~d}$ after formalin injection. Some rats were sacrificed at $1 \mathrm{~h}$ after formalin injection to collect plantar skin (from formalin-injected paw) and lumbar spinal cord (L4-L5) for HE and immunohistochemistry staining separately (Figure 1A). For evaluating the effect of UTI on the acute visceral pain, UTI was either intraperitoneal administrated $10 \mathrm{~min}$ before or $5 \mathrm{~min}$ after acetic acid intraperitoneal injection. Behavior test (writhing) was performed during the $1 \mathrm{~h}$ immediately after acetic acid injection. Some rats were sacrificed at $1 \mathrm{~h}$ after acetic acid injection to collecting peritoneum (parietal peritoneum) and spinal cord (T10-L2) for HE and immunohistochemistry staining separately (Figure 1B). The time point for behavior test and tissue collection was based on previous studies. ${ }^{23,25}$

\section{Statistical Analysis}

Data were analyzed using GraphPad Prism version 7.0 (GraphPad, San Diego, CA, USA) and all data were expressed as means \pm SEM. Differences in changes of values of each group were tested using $t$-tests and oneway or two-way ANOVA, followed by individual post hoc comparisons (Tukey's test). A level of $\mathrm{P}<0.05$ was accepted as significant.

\section{Results \\ Analgesic Effect of Ulinastatin on Formalin-Induced Acute Somatic Pain}

As previous description, intraplantar formalin injection evoked significant biphasic spontaneous pain-related behaviors, consisting flinching and licking/biting of the injected paw. ${ }^{23}$ During the 1-h time course of formalininduced spontaneous pain-related behaviors, the first transient phase lasted for the first $10 \mathrm{~min}$ and which was followed by the second prolonged phase from 15 to 60 min. As shown in Figure 2A and B, ulinastatin $(10,000$ and $50,000 \mathrm{U} / \mathrm{kg})$ i.p. pre-administration resulted in a dose-related suppressive effect on the development of licking behavior relative to the saline group, while the lowest dose $(2000 \mathrm{U} / \mathrm{kg})$ had no significant effect. It was noted that ulinastatin only had a suppressive effect on the licking duration in phase 2 with no influence in phase 1 

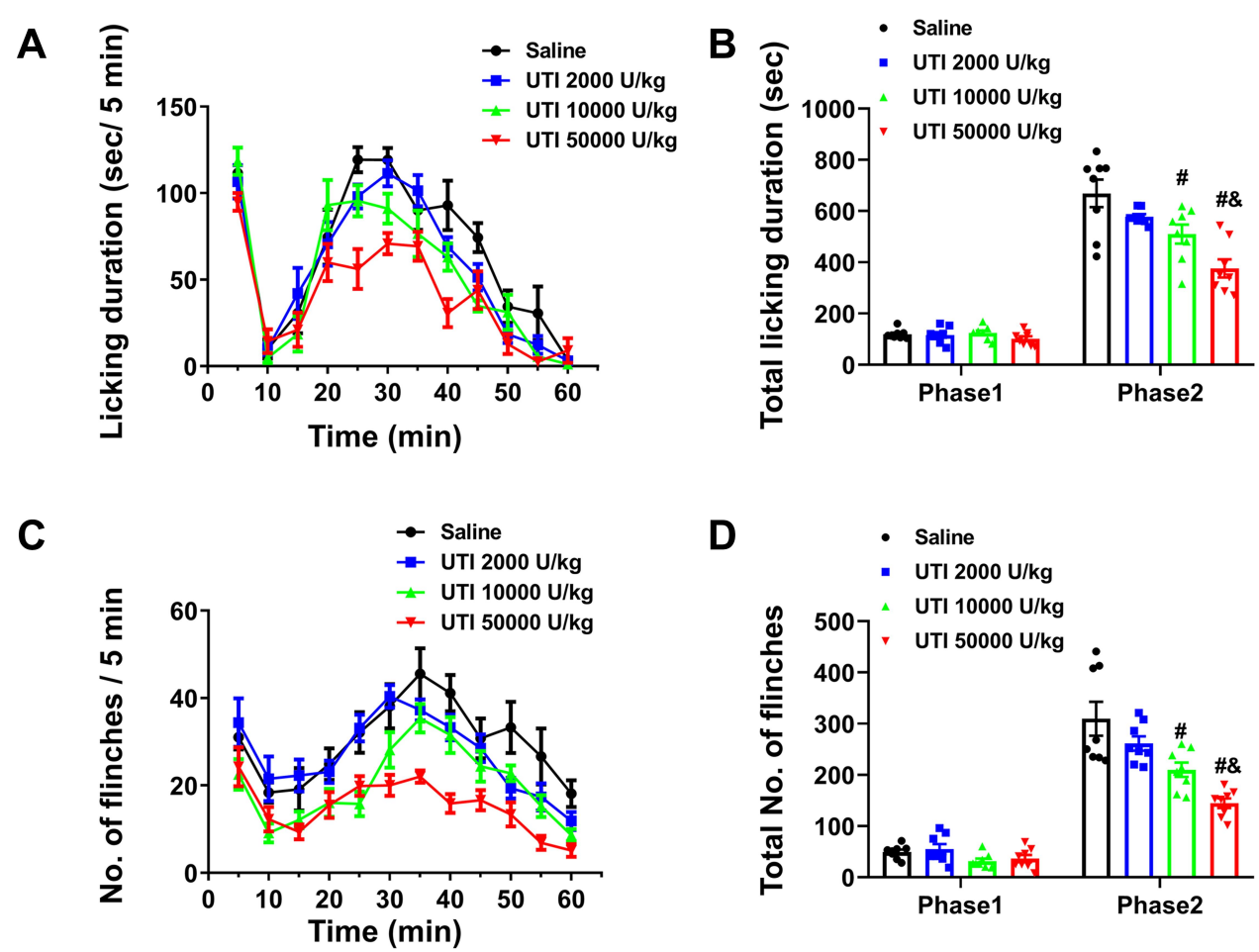

Figure 2 Effects of i.p. ulinastatin pre-treatment on formalin-induced spontaneous licking and flinching. (A) Curve graphs showing the effect of i.p. ulinastatin (2000, I0,000 and $50,000 \mathrm{U} / \mathrm{kg}$ ) pre-treatment on the licking time at each $5 \mathrm{~min}$ interval during $60 \mathrm{~min}$ immediately after intraplantar formalin injection. (B) Column graphs showing the effect of i.p. ulinastatin $(2000,10,000$ and 50,000 U/ kg) pre-treatment on the mean total licking time in 60 min course immediately after intraplantar formalin injection. (C) Curve graphs showing the effect of i.p. ulinastatin $(2000,10,000$ and 50,000 U/ kg) pre-treatment on the spontaneous flinches at each 5 min interval during 60 min immediately after intraplantar formalin injection. (D) Column graphs showing the effect of i.p. ulinastatin (2000, 10,000 and 50,000 U/ $/ \mathrm{kg})$ pre-treatment on the mean total flinches in 60 min course after immediately intraplantar formalin injection. $\mathrm{n}=8 /$ group, ${ }^{\#} \mathrm{P}<0.05$ vs Saline, ${ }^{\&} \mathrm{P}<0.05 \mathrm{vs} \mathrm{UTI} 10,000 \mathrm{U} / \mathrm{kg}$, two-way ANOVA followed by Tukey's post hoc test.

(Figure 2A and B). Moreover, ulinastatin (10,000 and $50,000 \mathrm{U} / \mathrm{kg}$ ) i.p. pre-administration also dosedependently prevented the development of formalininduced flinching behavior and the inhibitory effect only significantly presented in phase 2 (Figure $2 \mathrm{C}$ and D). There was no group difference in the number of flinches in phase 1 and the lowest dose $(2000 \mathrm{U} / \mathrm{kg})$ had no inhibitory effect during the 60 -min time course of formalin-induced flinching behavior (Figure 2C and D).

Next, we sought to identify the therapeutic effect of ulinastatin on formalin-induced spontaneous pain. As shown in Figure 3, ulinastatin $(50,000 \mathrm{U} / \mathrm{kg})$ i.p. postadministration resulted in a profound suppressive effect on licking and flinching behavior in phase 2, but not phase 1 , in comparison with the saline group.

\section{Analgesic Effect of Ulinastatin on Acetic Acid-Induced Acute Visceral Pain}

Intraperitoneal injection of $0.6 \%$ acetic acid induced visceral inflammatory pain in rats, as indicated by the contraction of abdominal muscles accompanied by extension of the forelimbs and elongation of the body. Ulinastatin $(10,000$ and 50,000 U/kg) i.p. pre-administration significantly prolonged the latency to first writhing and reduced the number of writhes during the 60 -min time course in a dose-dependent manner, while the lowest dose (2000 U/ $\mathrm{kg}$ ) of ulinastatin had no significant effect on the latency to first writhing and the number of writhes (Figure 4A and B). Giving the mean latency from acetic acid injection to first writhing was about $10 \mathrm{~min}$ in saline group, we performed ulinastatin $(50,000 \mathrm{U} / \mathrm{kg})$ i.p. administration at 5 min after acetic acid injection to examine the therapeutic effect of ulinastatin on acute visceral inflammatory pain. As shown in Figure 4C and D, ulinastatin $(50,000 \mathrm{U} / \mathrm{kg}) \mathrm{i}$. p. post-administration caused prolongation of the latency to first writhing and reduction of the number of writhes induced by acetic acid injection.

\section{Effect of Ulinastatin on the Paw Edema and Ulcer in the Formalin Test}

In line with previous study, the intraplantar injection of formalin into tissues induces local edema and ulcer in the ipsilateral paw. ${ }^{23}$ As shown in Figure 5, the paw 

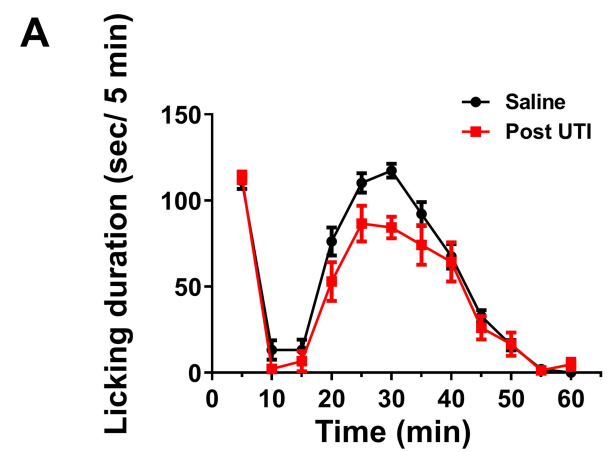

C

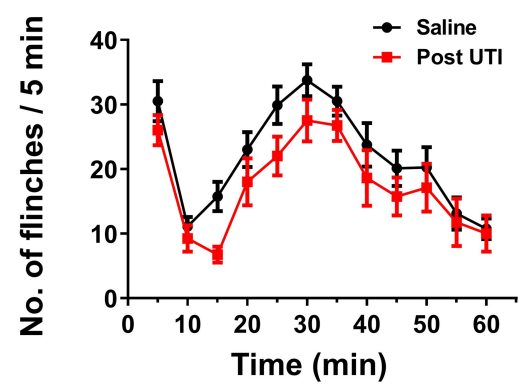

B

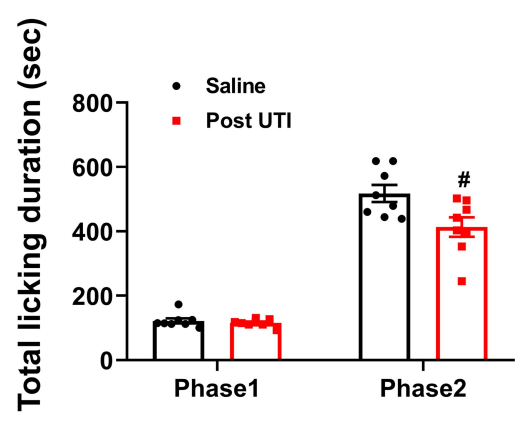

D

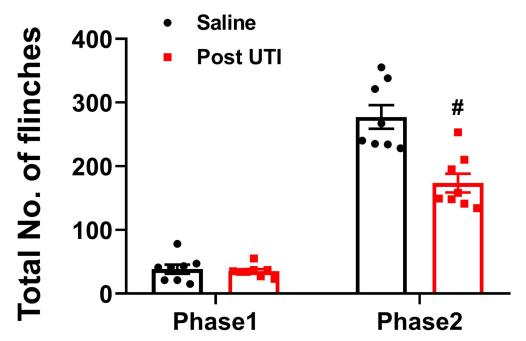

Figure 3 Effects of i.p. ulinastatin post-treatment on formalin-induced spontaneous licking and flinching. (A) Curve graphs showing the effect of i.p. ulinastatin ( $50,000 \mathrm{U} / \mathrm{kg}$ ) post-treatment on the licking time at each 5 min interval during 60 min immediately after intraplantar formalin injection. (B) Column graphs showing the effect of i.p. ulinastatin $(50,000 \mathrm{U} / \mathrm{kg}$ ) post-treatment on the mean total licking time in 60 min course immediately after intraplantar formalin injection. (C) Curve graphs showing the effect of i.p. ulinastatin $(50,000 \mathrm{U} / \mathrm{kg}$ ) post-treatment on the spontaneous flinches at each 5 min interval during 60 min immediately after intraplantar formalin injection. (D) Column graphs showing the effect of i.p. ulinastatin $(50,000 \mathrm{U} / \mathrm{kg})$ post-treatment on the mean total flinches in 60 min course after immediately intraplantar formalin injection. $n=8 /$ group, ${ }^{\#} \mathrm{P}<0.05$ vs Saline, two-way ANOVA followed by Tukey's post hoc test.

edema rapidly occurred at $2 \mathrm{~h}$, peaked at day 1 and maintained at least for 10 days. Ulinastatin $(10,000$ and $50,000 \mathrm{U} / \mathrm{kg}$ ) i.p. pre-administration significantly suppressed the magnitude of paw edema compared with the saline group, with the lowest dose (2000 U/ $\mathrm{kg}$ ) showing no suppressive effect (Figure 5A and B). However, ulinastatin $(50,000 \mathrm{U} / \mathrm{kg})$ i.p. postadministration could not reverse the formalin-induced paw edema compared to the saline group (Figure 5C and D). Similarly, ulinastatin i.p. pre-administration markedly inhibited the incidence of paw ulcers at day 3 and day 7, and increased the incidence of ulcers healing at day 10, compared with saline group (Figure $6 \mathrm{~A}$ and $\mathrm{B})$. Ulinastatin $(50,000 \mathrm{U} / \mathrm{kg})$ i.p. postadministration was also able to reduce the incidence of formalin-induced ulcers at day 3 and day 7, and the incidence of ulcers healing at day 10 was also higher in ulinastatin post-administration group, compared to the saline group (Figure 6C and D). All these results strongly suggested that ulinastatin could act on the inflammatory phase of formalin test.

\section{Anti-Inflammatory Activities of Ulinastatin in the Formalin Test}

We next sought to explore the effect of ulinastatin treatment on the local and central inflammatory reaction induced by intraplantar formalin injection. As shown in Figure $7 \mathrm{~A}$ and $\mathrm{B}$, ulinastatin significantly reduced the degree of inflammatory cell infiltration in formalininjected paw skin confirmed by H\&E staining. In sham group, the Iba1-positive cells in the ipsilateral lumbar spinal cord maintain a resting state characterized as a small soma bearing thin-branched or ramified processes (Figure 7C). After intraplantar formalin injection, Iba1positive cells in the ipsilateral lumbar spinal cord displayed as a significant activated morphology with marked cell bodies hypertrophy and retraction of cytoplasmic processes (Figure 7C). Quantitative analysis revealed that ulinastatin treatment dramatically reduced the number of activated microglia (Figure 7D). Moreover, the GFAP immunoreactivity in the ipsilateral spinal dorsal horn from intraplantar formalin injection group was also significantly increased compared with sham group 

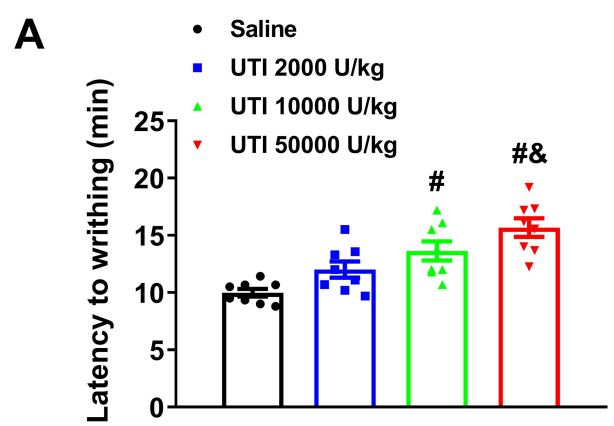

C

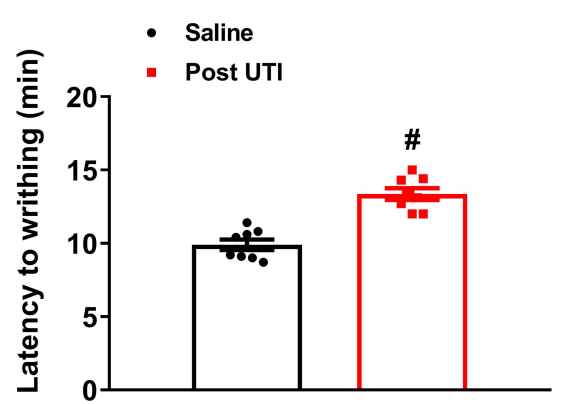

B

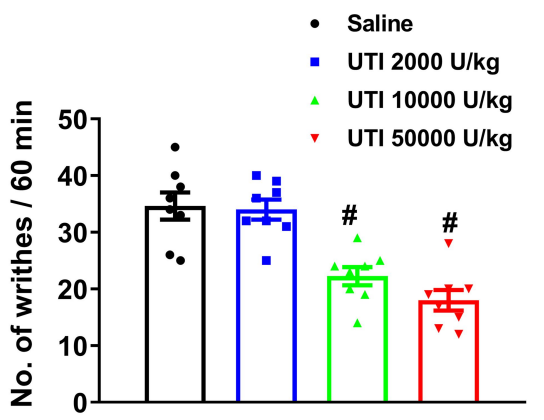

D

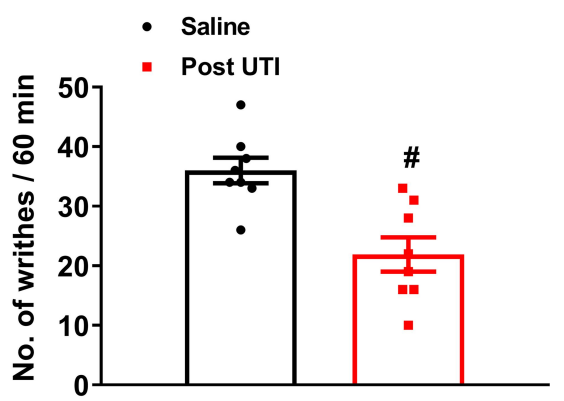

Figure 4 Effects of i.p. ulinastatin administration on acetic acid-induced spontaneous writhe. (A) Column graphs showing the effect of i.p. ulinastatin (2000, 10,000 and $50,000 \mathrm{U} / \mathrm{kg}$ ) pre-treatment on the writhes latency from i.p. acetic acid injection. (B) Column graphs showing the effect of i.p. ulinastatin (2000, 10,000 and $50,000 \mathrm{U} / \mathrm{kg}$ ) pretreatment on the mean total writhes in 60 min course immediately after i.p. acetic acid injection. n=8/group, ${ }^{\#} \mathrm{P}<0.05 \mathrm{vs} \mathrm{Saline,}{ }^{\&} \mathrm{P}<0.05 \mathrm{vs} U \mathrm{TII} 10,000 \mathrm{U} / \mathrm{kg}$, one-way ANOVA followed by Tukey's post hoc test. (C) Column graphs showing the effect of i.p. ulinastatin (50,000 U/kg) post-treatment on the writhes latency from i.p. acetic acid injection. (D) Column graphs showing the effect of i.p. ulinastatin (50,000 U/kg) post-treatment on the mean total writhes in 60 min course immediately after i.p. acetic acid injection. $\mathrm{n}=8 /$ group, ${ }^{\#} \mathrm{P}<0.05$ vs Saline, Student's unpaired $t$-test.

(Figure 7E). The quantitative analysis showed that ulinastatin treatment remarkably reduced the number of GFAPpositive astrocytes in the ipsilateral spinal dorsal horn than that of saline treatment (Figure 7F).

\section{Anti-Inflammatory Activities of \\ Ulinastatin in the Acetic Acid Test}

In the H\&E staining assay, acetic acid i.p. injection induced prominent inflammation in the peritoneum tissue manifesting as the more inflammatory cell infiltration, and which was distinctly alleviated by ulinastatin treatment (Figure 8A and B). As shown in Figure 8C and $\mathrm{D}$, acetic acid i.p. injection significantly induced the microglial activation in the spinal dorsal horn compared to sham group reflecting as the marked Iba1-positive cell body hypertrophy and retraction of cytoplasmic processes, while ulinastatin treatment was sufficient to reduce the number of activated microglia induced by acetic acid i.p. injection. The GFAP-positive astrocyte in the spinal dorsal horn was also increased after acetic acid i.p. injection, and which was prominently reduced by ulinastatin treatment compared with saline treatment (Figure 8E and F).

\section{Discussion}

It is well recognized that inflammatory somatic and visceral pain remain challenges in modern medicine. To help bridge the gap between preclinical knowledge and clinical management, several experimental animal models have been developed attempting to mimic human pathological pain syndrome. ${ }^{26}$ By using two classical pain model, formalin and acetic acid-induced writhing test, we evaluated the antinociceptive effect of ulinastatin on acute somatic and visceral pain, and the underlying mechanisms were also investigated. We for the first time found that both the pre-administration and post-administration of ulinastatin could significantly attenuate intraplantar formalin injection-induced acute somatic pain in a dose-related manner, and the formalin-induced paw edema and ulcer were also improved by ulinastatin. Furthermore, acetic acid i.p. injection-induced acute visceral pain was also prevented and reversed by ulinastatin. We further demonstrated that ulinastatin could significantly inhibit the local inflammatory cell infiltration in the injured paw and peritoneum tissue, and the microglial and astrocytic activation in the spinal dorsal horn induced by formalin and acetic acid were also dramatically prevented by ulinastatin, 
A

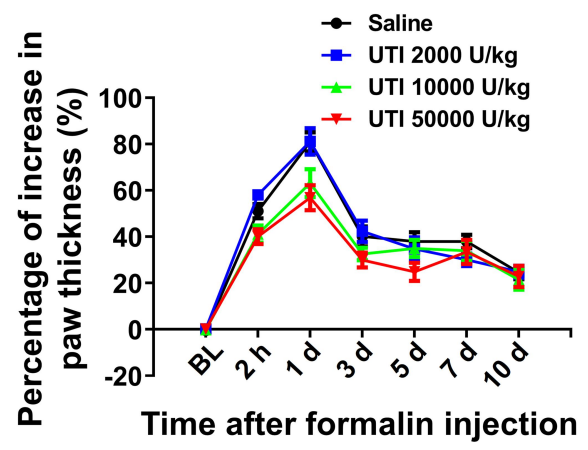

C

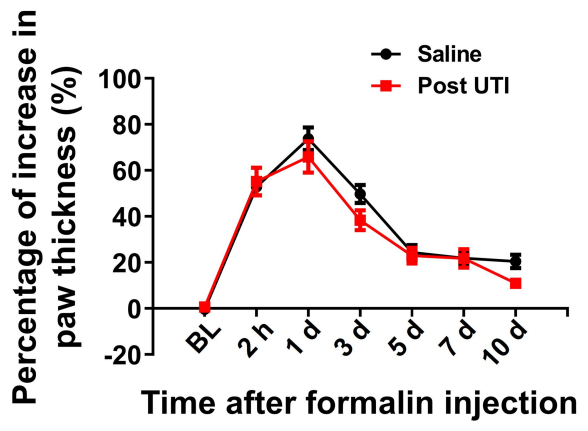

B - Saline

- UTI $2000 \mathrm{U} / \mathrm{kg}$

A UTI $10000 \mathrm{U} / \mathrm{kg}$

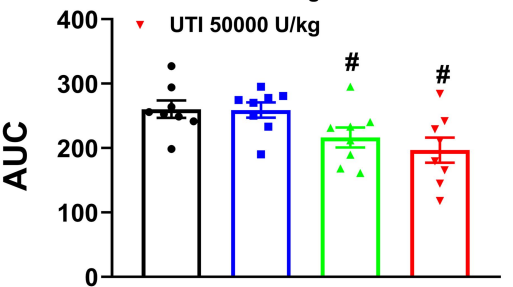

D

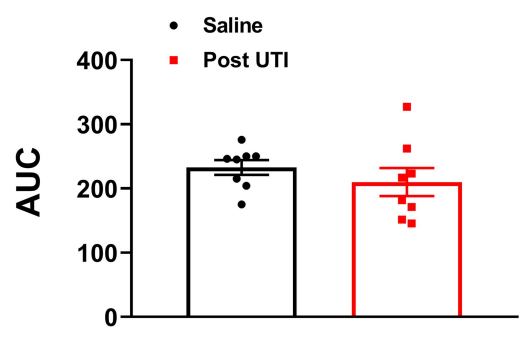

Figure 5 Effects of i.p. ulinastatin administration on formalin-induced paw edema. (A) Curve graphs showing the effect of i.p. ulinastatin (2000, 10,000 and $50,000 \mathrm{U} / \mathrm{kg})$ pretreatment on the paw edema at $2 \mathrm{~h}$ and day I, 3, 5, 7, 10 after intraplantar formalin injection. (B) Area under the curve (AUC) for different pre-treatment groups was calculated for statistical analysis. $n=8 /$ group, ${ }^{\#} \mathrm{P}<0.05$ vs Saline, one-way ANOVA followed by Tukey's post hoc test. (C) Curve graphs showing the effect of i.p. ulinastatin $(50,000 \mathrm{U} / \mathrm{kg}$ ) post-treatment on the paw edema at $2 \mathrm{~h}$ and day I, 3, 5, 7, 10 after intraplantar formalin injection. (D) Area under the curve (AUC) for post-treatment groups was calculated for statistical analysis. $\mathrm{n}=8 /$ group, Student's unpaired $t$-test.

suggesting that the antinociception of ulinastatin was attributed to its anti-inflammatory activities peripherally and centrally. Our present work provides scientific basis for the clinical use of ulinastatin for pain relief.

Pain is one of the most common symptoms of inflammatory disease which seriously affects patient's daily activities and quality of life. In the past decade, accumulating evidence demonstrated that various proteases participated in the pain modulation. ${ }^{12,27-30}$ Therefore, inhibition of protease may provide a new strategy for the treatment of pain and studying the modulatory effects of protease inhibitors on pain is considered an emerging area of interest. ${ }^{31}$ As a broadspectrum protease inhibitor, ulinastatin has been revealed to inhibit multiple pain-related proteinase such as trypsin, chymotrypsin, elastase and matrix metalloproteinase (MMP) and it was suggested to be a potential ideal pharmacological candidate for the treatment of severe neuropathic pain ${ }^{13,33-36}$. However, the research of ulinastatin on visceral pain is very limited, except for a clinical trial found that somatostatin combined with ulinastatin significantly shortened the duration of abdominal pain in acute pancreatitis compared with somatostatin alone, but the mechanism remains unclear. $^{37}$

In this study, we for the first time used formalin test to investigate the therapeutic effect of ulinastatin on acute inflammatory somatic pain. We selected formalin test here because it has several advantages over other models, in that little or no restraint is necessary, and no additional stimulus is required to evoke nocifensive behaviors, and behaviors can be scored over a prolonged period such that the precise onset and duration of analgesics can be assessed. We found that both pre-administration and postadministration of ulinastatin were effective to reduce formalin-induced paw flinching. In addition, the time spent in licking the injured paw was also significantly reduced by systemic administration of ulinastatin. It was notable that ulinastatin exerted function only in second phase (phase 2) of formalin-provoked spontaneous nocifensive response with no significant effect in first phase (phase 1). Fundamentally, the two phases of formalin-induced pain response are considered to be associated, at least partially, with distinct mechanisms. The first phase of activity (0-10 
A

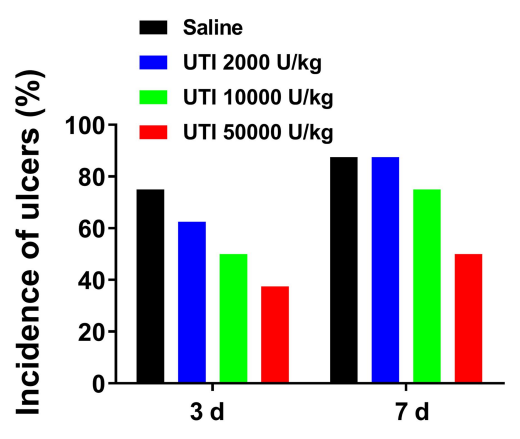

Time after formalin injection

C

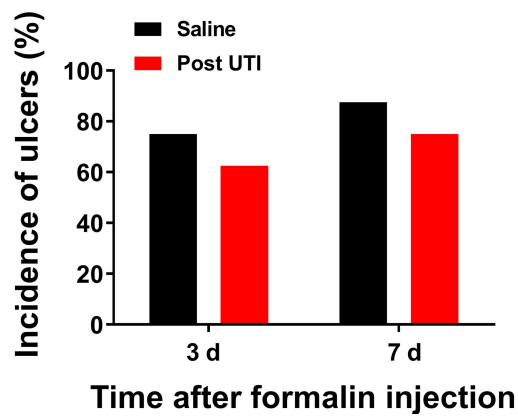

B

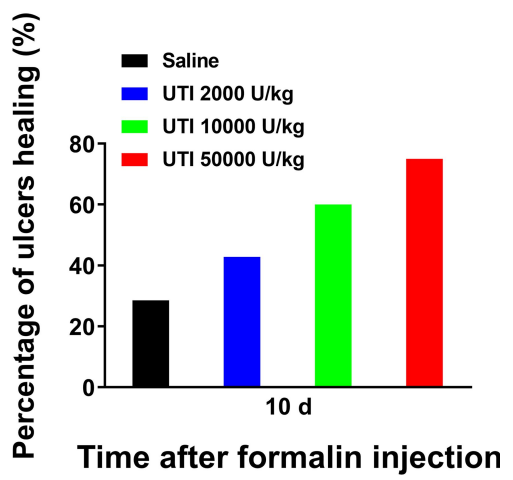

D

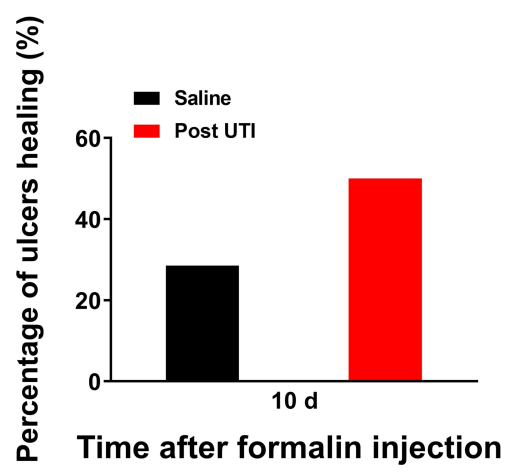

Figure 6 Effects of i.p. ulinastatin administration on formalin-induced ulcer forming and healing. (A) Column graphs showing the effect of i.p. ulinastatin (2000, 10,000 and $50,000 \mathrm{U} / \mathrm{kg}$ ) pre-treatment on the incidence of ulcers at day 3 and day 7 after intraplantar formalin injection. (B) Column graphs showing the effect of i.p. ulinastatin (2000, 10,000 and $50,000 \mathrm{U} / \mathrm{kg}$ ) pre-treatment on ulcers healing at day 10 after intraplantar formalin injection. (C) Column graphs showing the effect of i.p. ulinastatin (50,000 U/kg) post-treatment on the incidence of ulcers at day 3 and day 7 after intraplantar formalin injection. (D) Column graphs showing the effect of i.p. ulinastatin (50,000 $\mathrm{U} / \mathrm{kg}$ ) posttreatment on ulcers healing at day 10 after intraplantar formalin injection.

min; neurogenic pain) occurring immediately following injection reflects a direct activation of peripheral nociceptors, while the second phase of activity (15-60 min; inflammatory pain) is associated with the development of an inflammatory response and the release of nociceptive mediators which are responsible for sensitization of primary and spinal sensory neurons and subsequent activation of the nociceptors. ${ }^{26,38}$ The inhibitory effect of ulinastatin on phase 2 of formalin test strongly suggested that its activity could be resultant from the antiinflammatory action. Moreover, we found ulinastatin could also persistently inhibit formalin-induced paw edema and ulcer which corroborated the antiinflammatory effect of ulinastatin. Based on these findings, we tried to clarify the analgesic mechanism of ulinastatin by detecting the glial activation in the spinal cord and inflammatory cell infiltration in injured paw. We verified that systemic administration of ulinastatin noticeably prevented the activation of microglia and astrocyte in the ipsilateral spinal dorsal horn induced by intraplantar formalin injection. Actually, a large number studies have demonstrated that peripheral formalin injection significantly evoked spinal microglial and astrocytic activation. $^{39}$ The analgesic potential of ulinastatin observed in present investigation is consistent with earlier reports on glial inhibitor, like minocycline, L- $\alpha$ aminoadipate and fluorocitrate, that largely attenuated the second phase of formalin-induced pain responses. $^{40-43}$ Previous studies have demonstrated that ulinastatin protein could be found in the brain tissue and cerebrospinal fluid in human and rodents but its mRNA has been detected mainly in the liver, suggested that systemic ulinastatin was able to enter the central nervous system to play a role. ${ }^{4-46}$ The inhibitory effect of ulinastatin on glial cells in the central nervous system observed in the present study was consistent with previous reports of its effect on other models. In the rat sciatic nerve ligation model, ulinastatin was able to down-regulate P2Y2 receptor and inhibit the abnormal microglia activation in the spinal dorsal horn and thus prevented the development of mechanical allodynia and thermal hypersensitivity. $^{15}$ In experimental autoimmune 
A

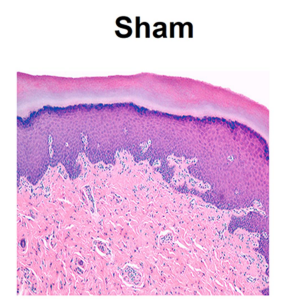

Formalin+Saline
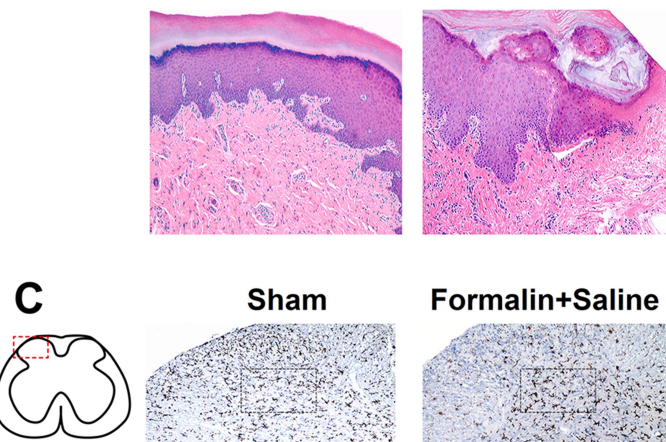

lba1

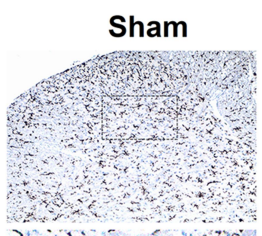

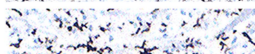
retery $4 x+2$

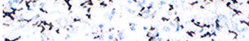
$\therefore=x^{2}-3$ F $+4 x^{2}+4$
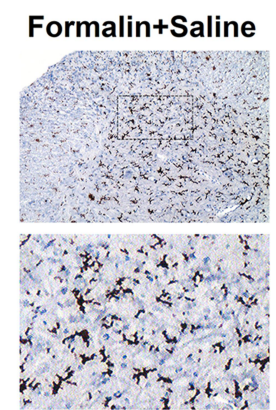

Formalin+Saline
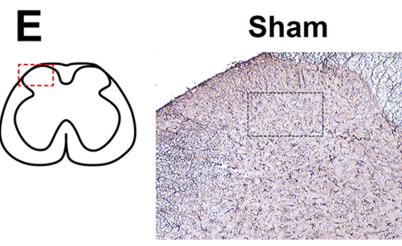

GFAP

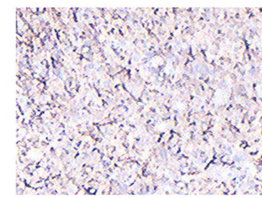

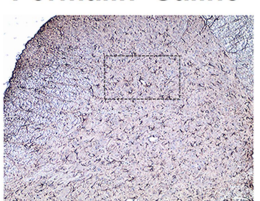

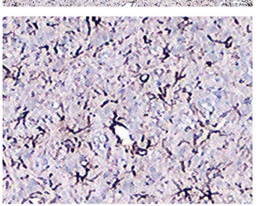

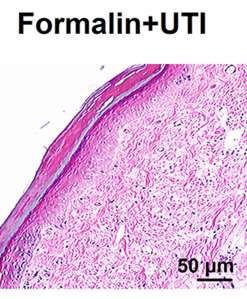
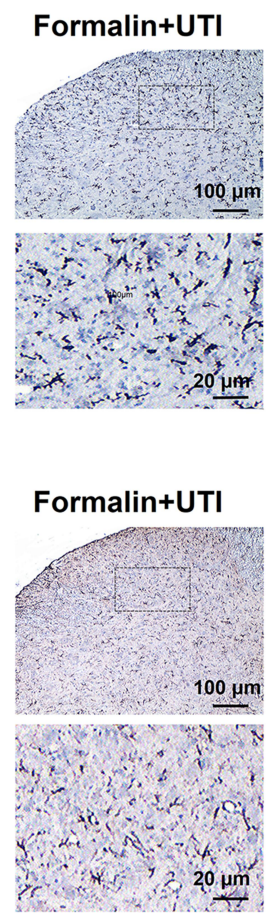

B

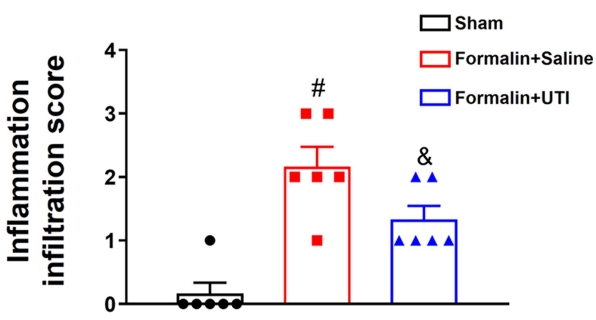

D

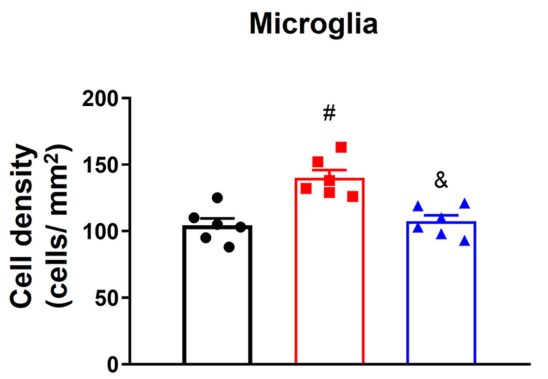

$\mathbf{F}$

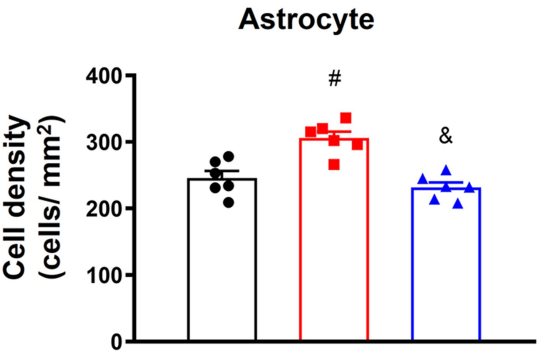

Figure 7 Effects of ulinastatin on formalin-induced local and central inflammation. (A) Representative H\&E staining of the plantar skin taken near the intraplantar injection site from sham group and formalin group receiving saline or ulinastatin treatment. Scale bars, $50 \mu \mathrm{m}$. (B) Quantitative scoring showed ulinastatin treatment dramatically reduced intraplantar formalin injection-induced inflammation infiltration in plantar skin. ${ }^{*} P<0.05$ vs Sham, ${ }^{\circledR} P<0.05$ vs formalin+saline. (C) Representative immunohistochemistry staining for Iba I in ipsilateral spinal dorsal horn (L4-L5) from sham group and formalin group receiving saline or ulinastatin treatment. (D) Quantitative analyses showed that ulinastatin treatment significantly reduced the number of activated microglia in formalin group compared to the saline treatment. ${ }^{\#} \mathrm{P}<0.05 \mathrm{vs}$ Sham, ${ }^{\circledR} \mathrm{P}<0.05 \mathrm{vs}$ formalin+saline, one-way ANOVA followed by Tukey's post hoc test. (E) Representative immunohistochemistry staining for GFAP in ipsilateral spinal dorsal horn (L4-L5) from sham group and formalin group receiving saline or ulinastatin treatment. $(\mathbf{F})$ Quantitative analyses showed that ulinastatin treatment significantly reduced the number of activated astrocyte in formalin group compared to the saline treatment. ${ }^{\#} \mathrm{P}<0.05$ vs Sham, ${ }^{\circledR} \mathrm{P}<0.05$ vs formalin + saline, one-way ANOVA followed by Tukey's post hoc test.

encephalomyelitis and cecal ligation and puncture model, systemic administration of ulinastatin could also decrease the activation of microglia in the spinal cord and exert its anti-inflammatory effects. ${ }^{4,48}$ It is well known that ulinastatin could inhibit inflammation by suppressing the infiltration of neutrophils and release of elastase and inflammatory mediators from neutrophils. ${ }^{49}$ As expecting, our result showed that the local infiltration of inflammatory cells induced by intraplantar formalin injection was also prevented by systemic administration of ulinastatin which might be related to the effect of ulinastatin on relieving paw edema. The effect of ulinastatin on improving formalin-induced ulcer might also be attributed to its inhibition of inflammatory cell infiltration, because in ulcers caused by other causes, it has been confirmed that the degree of neutrophil infiltration is related to the severity of ulcers. ${ }^{50-52}$

The acetic acid-induced abdominal writhing behavior is a typical model of visceral pain employed as a screening tool for the assessment of antinociceptive activity of new analgesic agents. ${ }^{53}$ It has been suggested that acetic acid injection into the peritoneal cavity led to inflammatory reaction in visceral organs and peritoneum by provoking the release of inflammatory mediators, such as prostaglandins, bradykinin, substance $\mathrm{P}$ and cytokines, which could directly activate visceral and somatic nociceptors innervating the peritoneum and eventually resulted in the development of pain and the behavior of abdominal 
A

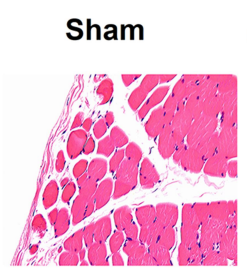

Acetic acid+Saline

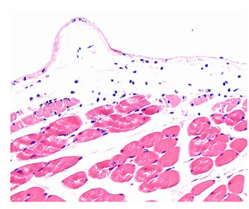

C

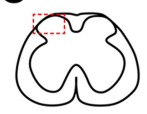

Iba1
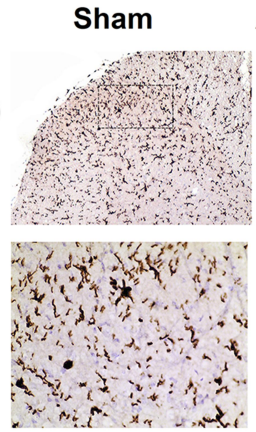

E

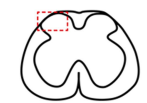

GFAP
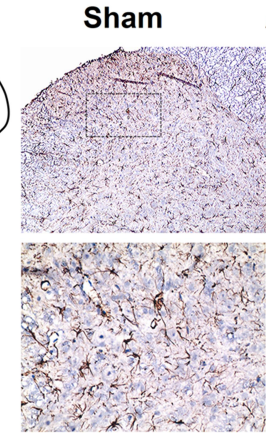

Acetic acid+Saline
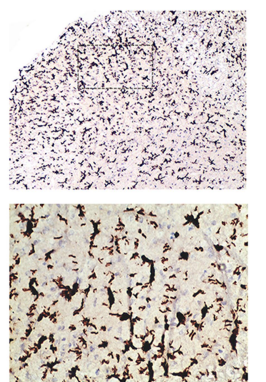

Acetic acid+Saline
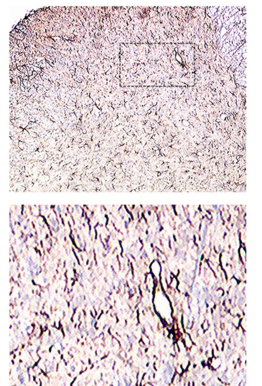

Acetic acid+UTI

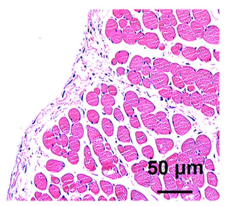

Acetic acid+UTI

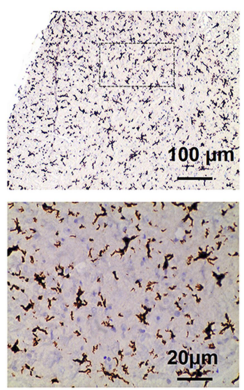

Acetic acid+UTI

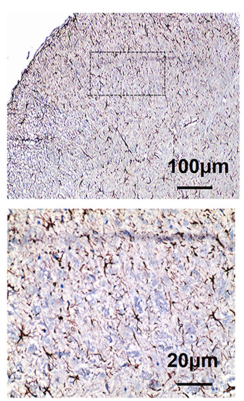

B

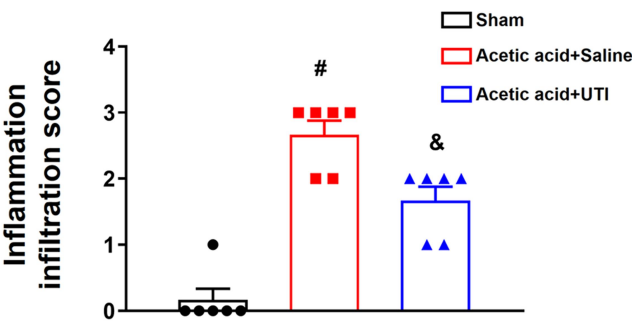

D

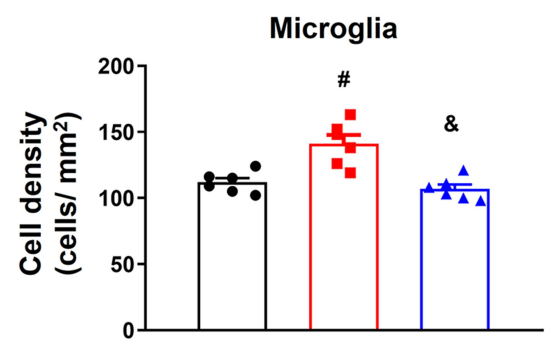

$\mathbf{F}$

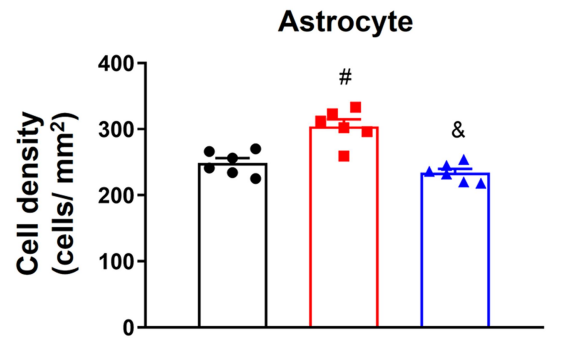

Figure 8 Effects of ulinastatin on acetic acid-induced local and central inflammation. (A) Representative H\&E staining of the peritoneum tissue taken from sham group and acetic acid group receiving saline or ulinastatin treatment. Scale bars, $50 \mu \mathrm{m}$. (B) Quantitative scoring showed ulinastatin treatment dramatically reduced intraperitoneal acetic acid injection-induced inflammation infiltration in peritoneum tissue. ${ }^{\#} \mathrm{P}<0.05$ vs Sham, ${ }^{\circledR} \mathrm{P}<0.05$ vs acetic acid+saline. (C) Representative immunohistochemistry staining for Ibal in spinal dorsal horn (TIO-L2) from sham group and acetic acid group receiving saline or ulinastatin treatment. (D) Quantitative analyses showed that ulinastatin treatment significantly reduced the number of activated microglia in acetic acid group compared to the saline treatment. ${ }^{\#} \mathrm{P}<0.05$ vs Sham, ${ }^{\&} \mathrm{P}<0.05$ vs acetic acid + saline, one-way ANOVA followed by Tukey's post hoc test. (E) Representative immunohistochemistry staining for GFAP in spinal dorsal horn (TI0-L2) from sham group and acetic acid group receiving saline or ulinastatin treatment. (F) Quantitative analyses showed that ulinastatin treatment significantly reduced the number of activated astrocyte in acetic acid group compared to the saline treatment. ${ }^{\#} \mathrm{P}<0.05$ vs Sham, ${ }^{\circledR} \mathrm{P}<0.05$ vs acetic acid + saline, one-way ANOVA followed by Tukey's post hoc test.

constrictions. $^{54-58}$ Our present study showed that systemic administration of ulinastatin not only reduced the total number of writhes but also delayed the occurrence of writhing. These data supported the potential of ulinastatin in visceral pain probably involving an anti-inflammatory component. Even though we did not detect the changes of inflammatory mediators in the abdominal cavity, we here observed that acetic acid-induced infiltration of inflammatory cells in the peritoneum tissue decreased significantly after systemic administration of ulinastatin in H\&E staining assay, which reinforced previous study that ulinastatin ameliorated the number of infiltrated inflammatory cell in cecal ligation and puncture induced sepsis. ${ }^{59}$ In addition to the local inflammation evoked by acetic acid, the role of spinal inflammatory reaction, including glial activation and pro-inflammatory cytokines release, in acetic acidinduced writhing response has also been reported. ${ }^{60-62}$ Previous studies verified that both minocycline and fluorocitrate were able to markedly reduce acetic acid-induced acute visceral nociception. ${ }^{62,63}$ In this point, we for the first time provided evidence that ulinastatin inhibited the activity of microglia and astrocytes in the spinal cord with visceral pain.

Indeed, the beneficial effect of ulinastatin on other types of pain, such as neuropathic pain, myocardial infarction and chronic pancreatitis, has also been reported. ${ }^{14,64,65}$ In our recent unpublished study, we found that ulinastatin could also alleviate postoperative pain without side-effects, 
including sedation and tolerance, which is common in the use of opioids. ${ }^{66}$ Even for the high-risk patients, such as shock, severe sepsis, acute respiratory distress syndrome and renal failure, ulinastatin was also recommended and showed obvious therapeutic advantages. ${ }^{67-69}$ Collectively, ulinastatin might be a potential ideal analgesic agent with broader spectrum of indications and more safety over NSAIDs and opioids.

In conclusion, the results of the present study demonstrated, for the first time, that ulinastatin has a doserelated, analgesic action in formalin test and writhing test, suggesting that ulinastatin might represent potential therapeutic options for the treatment of acute somatic and visceral pain. In addition, we verified that the analgesic effect of ulinastatin attributed to its inhibition on both of the peripheral and spinal inflammatory reaction, which might shed light on the mechanism of somatic and visceral pain.

\section{Acknowledgments}

This work was supported by grants from the National Natural Science Foundation of China (NO. 81801101, NO.81870828, NO.81801118), the Natural Science Foundation of Fujian Province (NO.2019J05145) and the Outstanding Youth Project initiated by 900 Hospital (NO.2017Q1). The funders had no role in study design, data collection and analysis, decision to publish, or preparation of the manuscript.

\section{Disclosure}

The authors have declared that no competing interests exist in this work.

\section{References}

1. Goldberg DS, McGee SJ. Pain as a global public health priority. $B M C$ Public Health. 2011;11:770. doi:10.1186/1471-2458-11-770

2. Li JX. Combining opioids and non-opioids for pain management: current status. Neuropharmacology. 2019;158:107619. doi:10.1016/j. neuropharm.2019.04.025

3. Eccleston C, Cooper TE, Fisher E, Anderson B, Wilkinson NM. Nonsteroidal anti-inflammatory drugs (NSAIDs) for chronic non-cancer pain in children and adolescents. Cochrane Database Syst Rev. 2017;8(8):D12537. doi:10.1002/14651858.CD012563.pub2

4. Ballantyne JC. Opioids for the treatment of chronic pain: mistakes made, lessons learned, and future directions. Anesth Analg. 2017;125 (5):1769-1778. doi:10.1213/ANE.0000000000002500

5. Ho KY, Gwee KA, Cheng YK, Yoon KH, Hee HT, Omar AR. Nonsteroidal anti-inflammatory drugs in chronic pain: implications of new data for clinical practice. J Pain Res. 2018;11:1937-1948. doi:10.2147/JPR.S168188
6. Volkow N, Benveniste H, McLellan AT. Use and misuse of opioids in chronic pain. Annu Rev Med. 2018;69:451-465. doi:10.1146/ annurev-med-011817-044739

7. Dale C, Vergnolle N. Protease signaling to G protein-coupled receptors: implications for inflammation and pain. $J$ Recept Signal Transduct Res. 2008;28(1-2):29-37. doi:10.1080/107998908019 41913

8. Paszcuk AF, Quintão NL, Fernandes ES, et al. Mechanisms underlying the nociceptive and inflammatory responses induced by trypsin in the mouse paw. Eur $J$ Pharmacol. 2008;581(1-2):204-215. doi:10.1016/j.ejphar.2007.11.025

9. Vergnolle N, Bunnett NW, Sharkey KA, et al. Proteinase-activated receptor-2 and hyperalgesia: a novel pain pathway. Nat Med. 2001;7 (7):821-826. doi:10.1038/89945

10. Cenac N, Coelho AM, Nguyen C, et al. Induction of intestinal inflammation in mouse by activation of proteinase-activated receptor-2. Am J Pathol. 2002;161(5):1903-1915. doi:10.1016/ S0002-9440(10)64466-5

11. Cenac N, Andrews $\mathrm{CN}$, Holzhausen M, et al. Role for protease activity in visceral pain in irritable bowel syndrome. J Clin Invest. 2007;117(3):636-647. doi:10.1172/JCI29255

12. Ceuleers H, Hanning N, Heirbaut J, et al. Newly developed serine protease inhibitors decrease visceral hypersensitivity in a post-inflammatory rat model for irritable bowel syndrome. $\mathrm{Br}$ J Pharmacol. 2018;175(17):3516-3533. doi:10.1111/bph.14396

13. Vicuna L, Strochlic DE, Latremoliere A, et al. The serine protease inhibitor SerpinA3N attenuates neuropathic pain by inhibiting $\mathrm{T}$ cell-derived leukocyte elastase. Nat Med. 2015;21(5):518-523. doi: $10.1038 / \mathrm{nm} .3852$

14. Nie B, Zhang S, Huang Z, et al. Synergistic interaction between dexmedetomidine and ulinastatin against vincristine-induced neuropathic pain in rats. J Pain. 2017;18(11):1354-1364. doi:10.1016/j. jpain.2017.06.007

15. Shi Y, Qin W, Nie F, Wen H, Lu K, Cui J. Ulinastatin attenuates neuropathic pain via the ATP/P2Y2 receptor pathway in rat models. Gene. 2017;627:263-270. doi:10.1016/j.gene.2017.06.045

16. Ouyang H, Nie B, Wang P, et al. Ulinastatin attenuates neuropathic pain induced by L5-VRT via the calcineurin/IL-10 pathway. Mol Pain. 2016;12:174480691664678. doi:10.1177/1744806916646785

17. Marcil J, Walczak JS, Guindon J, Ngoc AH, Lu S, Beaulieu P. Antinociceptive effects of tetrodotoxin (TTX) in rodents. $\mathrm{Br}$ J Anaesth. 2006;96(6):761-768. doi:10.1093/bja/ael096

18. Al-Khrasani M, Lackó E, Riba P, et al. The central versus peripheral antinociceptive effects of $\mu$-opioid receptor agonists in the new model of rat visceral pain. Brain Res Bull. 2012;87(2-3):238-243. doi:10.1016/j.brainresbull.2011.10.018

19. Lackó E, Riba P, Giricz Z, et al. New morphine analogs produce peripheral antinociception within a certain dose range of their systemic administration. J Pharmacol Exp Ther. 2016;359(1):171-181. doi:10.1124/jpet.116.233551

20. Stepanovic-Petrovic RM, Micov AM, Tomic MA, Kovacevic JM, Boškovic BD. Antihyperalgesic/antinociceptive effects of ceftriaxone and its synergistic interactions with different analgesics in inflammatory pain in rodents. Anesthesiology. 2014;120(3):737-750. doi:10.1097/ALN.0000435833.33515.ba

21. Padi SS, Jain NK, Singh S, Kulkarni SK. Pharmacological profile of parecoxib: a novel, potent injectable selective cyclooxygenase-2 inhibitor. Eur J Pharmacol. 2004;491(1):69-76. doi:10.1016/j. ejphar.2004.03.013

22. Fu KY, Light AR, Maixner W. Long-lasting inflammation and long-term hyperalgesia after subcutaneous formalin injection into the rat hindpaw. J Pain. 2001;2(1):2-11. doi:10.1054/jpai.2001.9804

23. Yin JB, Zhou KC, Wu HH, et al. Analgesic effects of DangguiShaoyao-San on various "phenotypes" of nociception and inflammation in a formalin pain model. Mol Neurobiol. 2016;53 (10):6835-6848. doi:10.1007/s12035-015-9606-3 
24. Gomez-Brouchet A, Blaes N, Mouledous L, et al. Beneficial effects of levobupivacaine regional anaesthesia on postoperative opioid induced hyperalgesia in diabetic mice. J Transl Med. 2015;13:208. doi:10.1186/s12967-015-0575-0

25. Qin M, Wang JJ, Cao R, et al. The lumbar spinal cord glial cells actively modulate subcutaneous formalin induced hyperalgesia in the rat Neurosci Res. 2006;55(4):442-450. doi:10.1016/j.neures.2006.04.017

26. Yam MF, Loh YC, Oo CW, Basir R. Overview of neurological mechanism of pain profile used for animal "pain-like" behavioral study with proposed analgesic pathways. Int J Mol Sci. 2020;21 (12):4355. doi:10.3390/ijms21124355

27. Vergnolle N. Protease-activated receptors as drug targets in inflammation and pain. Pharmacol Ther. 2009;123(3):292-309. doi:10.1016/j.pharmthera.2009.05.004

28. Cattaruzza F, Amadesi S, Carlsson JF, et al. Serine proteases and protease-activated receptor 2 mediate the proinflammatory and algesic actions of diverse stimulants. $B r J$ Pharmacol. 2014;171 (16):3814-3826. doi:10.1111/bph.12738

29. Muley MM, Reid AR, Botz B, Bolcskei K, Helyes Z, McDougall JJ. Neutrophil elastase induces inflammation and pain in mouse knee joints via activation of proteinase-activated receptor-2. $\mathrm{Br}$ J Pharmacol. 2016;173:766-777. doi:10.1111/bph.13237

30. Ishikura $H$, Nishimura $S$, Matsunami $M$, et al. The proteinase inhibitor camostat mesilate suppresses pancreatic pain in rodents. Life Sci. 2007;80(21):1999-2004. doi:10.1016/j.lfs.2007.02.044

31. Bali KK, Kuner R. Therapeutic potential for leukocyte elastase in chronic pain states harboring a neuropathic component. Pain. 2017;158(11):2243-2258. doi:10.1097/j.pain.0000000000001032

32. Li XF, Zhang XJ, Zhang C, et al. Ulinastatin protects brain against cerebral ischemia/reperfusion injury through inhibiting MMP-9 and alleviating loss of ZO-1 and occludin proteins in mice. Exp Neurol. 2018;302:68-74. doi:10.1016/j.expneurol.2017.12.016

33. Hoogerwerf WA, Shenoy M, Winston JH, Xiao SY, He Z, Pasricha PJ. Trypsin mediates nociception via the proteinase-activated receptor 2: a potentially novel role in pancreatic pain. GASTROENTEROLOGY. 2004;127(3):883-891. doi:10.1053/j. gastro.2004.07.002

34. Umeadi C, Kandeel F, Al-Abdullah IH. Ulinastatin is a novel protease inhibitor and neutral protease activator. Transplant Proc. 2008;40(2):387-389. doi:10.1016/j.transproceed.2008.01.034

35. Hua G, Haiping Z, Baorong H, Dingjun H. Effect of ulinastatin on the expression of iNOS, MMP-2, and MMP-3 in degenerated nucleus pulposus cells of rabbits. Connect Tissue Res. 2013;54(1):29-33. doi: $10.3109 / 03008207.2012 .716882$

36. Muley MM, Krustev E, Reid AR, McDougall JJ. Prophylactic inhibition of neutrophil elastase prevents the development of chronic neuropathic pain in osteoarthritic mice. J Neuroinflammation. 2017;14 (1):168. doi:10.1186/s12974-017-0944-0

37. Wang G, Liu Y, Zhou SF, et al. Effect of somatostatin, ulinastatin and gabexate on the treatment of severe acute pancreatitis. Am J Med Sci. 2016;351(5):506-512. doi:10.1016/j.amjms.2016.03.013

38. Tjolsen A, Berge OG, Hunskaar S, Rosland JH, Hole K. The formalin test: an evaluation of the method. Pain. 1992;51(1):5-17. doi:10.1016/0304-3959(92)90003-T

39. Sweitzer SM, Colburn RW, Rutkowski M, DeLeo JA. Acute peripheral inflammation induces moderate glial activation and spinal IL-1beta expression that correlates with pain behavior in the rat. Brain Res. 1999;829(1-2):209-221. doi:10.1016/s0006-8993(99)01326-8

40. Bastos LF, Prazeres JD, Godin AM, et al. Sex-independent suppression of experimental inflammatory pain by minocycline in two mouse strains. Neurosci Lett. 2013;553:110-114. doi:10.1016/j.neulet.20 13.08 .026

41. Chen G, Luo X, Qadri MY, Berta T, Ji RR. Sex-dependent glial signaling in pathological pain: distinct roles of spinal microglia and astrocytes. Neurosci Bull. 2018;34(1):98-108. doi:10.1007/s12264017-0145-y
42. Cheng XE, Peng $\mathrm{HZ}, \mathrm{Hu} \mathrm{XX}$, et al. Minocycline inhibits formalin-induced inflammatory pain and the underlying mechanism. Beijing Da Xue Xue Bao Yi Xue Ban. 2018;50(5):797-804.

43. Lu JM, Gong N, Wang YC, Wang YX. D-Amino acid oxidase-mediated increase in spinal hydrogen peroxide is mainly responsible for formalin-induced tonic pain. $\mathrm{Br} J$ Pharmacol. 2012;165(6):1941-1955. doi:10.1111/j.1476-5381.2011.01680.x

44. Iwama H, Ohmori S, Tsutsumi T. Detectable concentrations of urinary trypsin inhibitor in cerebrospinal fluid. J Neurosurg Anesthesiol. 2000;12(1):29-32. doi:10.1097/00008506-200001000-00006

45. Shikimi T, Hattori K, Takaori S. Existence of a human urinary trypsin inhibitor (urinastatin)-like substance in the rat brain. Jpn J Pharmacol. 1992;60(2):97-103. doi:10.1254/jjp.60.97

46. Shikimi T, Suzuki S, Wessel T, Joh TH, Hattori K, Takaori S. Human urinary trypsin inhibitor (urinastatin)-like substance in mouse liver. Life Sci. 1992;50(19):1399-1406. doi:10.1016/0024-3205(92)90258-q

47. Feng M, Shu Y, Yang Y, et al. Ulinastatin attenuates experimental autoimmune encephalomyelitis by enhancing anti-inflammatory responses. Neurochem Int. 2014;64:64-72. doi:10.1016/j. neuint.2013.11.007

48. Xie F, Min S, Chen J, Yang J, Wang X. Ulinastatin inhibited sepsis-induced spinal inflammation to alleviate peripheral neuromuscular dysfunction in an experimental rat model of neuromyopathy. $J$ Neurochem. 2017;143(2):225-235. doi:10.1111/jnc.14145

49. Linder A, Russell JA. An exciting candidate therapy for sepsis: ulinastatin, a urinary protease inhibitor. Intensive Care Med. 2014;40(8):1164-1167. doi:10.1007/s00134-014-3366-9

50. Yoshikawa T, Naito Y. The role of neutrophils and inflammation in gastric mucosal injury. Free Radic Res. 2000;33(6):785-794. doi:10.1080/10715760000301301

51. Diegelmann RF. Excessive neutrophils characterize chronic pressure ulcers. Wound Repair Regen. 2003;11(6):490-495. doi:10.1046/ j.1524-475x.2003.11617.x

52. Shimizu N, Watanabe T, Arakawa T, Fujiwara Y, Higuchi K, Kuroki T. Pentoxifylline accelerates gastric ulcer healing in rats: roles of tumor necrosis factor alpha and neutrophils during the early phase of ulcer healing. Digestion. 2000;61(3):157-164. doi:10.1159/000007752

53. Ribeiro RA, Vale ML, Thomazzi SM, et al. Involvement of resident macrophages and mast cells in the writhing nociceptive response induced by zymosan and acetic acid in mice. Eur J Pharmacol. 2000;387(1):111-118. doi:10.1016/s0014-2999(99)00790-6

54. Czeschik JC, Hagenacker T, Schafers M, Busselberg D. TNF-alpha differentially modulates ion channels of nociceptive neurons. Neurosci Lett. 2008;434(3):293-298. doi:10.1016/j.neulet.2008.01.070

55. Gomez R, Por ED, Berg KA, Clarke WP, Glucksman MJ, Jeske NA. Metallopeptidase inhibition potentiates bradykinin-induced hyperalgesia. Pain. 2011;152(7):1548-1554. doi:10.1016/j.pain.2011.02.044

56. Taghi MM, Naghizadeh B, Ghorbanzadeh B, Farbood Y. Central and peripheral antinociceptive effects of ellagic acid in different animal models of pain. Eur J Pharmacol. 2013;707(1-3):46-53. doi:10.1016/j.ejphar.2013.03.031

57. Abdulkhaleq LA, Assi MA, Abdullah R, Zamri-Saad M, Taufiq-Yap YH, Hezmee M. The crucial roles of inflammatory mediators in inflammation: a review. Vet World. 2018;11(5):627-635. doi:10.14202/vetworld.2018.627-635

58. Bueno L, Fioramonti J. Visceral perception: inflammatory and non-inflammatory mediators. GUT. 2002;51(Suppl 1):i19-i23. doi:10.1136/gut.51.suppl_1.i19

59. Song Y, Miao S, Li Y, Fu H. Ulinastatin attenuates liver injury and inflammation in a cecal ligation and puncture induced sepsis mouse model. J Cell Biochem. 2019;120(1):417-424. doi:10.1002/jcb.27396

60. Gadotti VM, Martins DF, Pinto HF, et al. Diacerein decreases visceral pain through inhibition of glutamatergic neurotransmission and cytokine signaling in mice. Pharmacol Biochem Behav. 2012;102 (4):549-554. doi:10.1016/j.pbb.2012.06.018 
61. Arana-Argaez VE, Dominguez F, Moreno DA, et al. Antiinflammatory and antinociceptive effects of an ethanol extract from Senna septemtrionalis. Inflammopharmacology. 2020;28(2):541-549. doi:10.1007/s10787-019-00657-7

62. Zhao J, Li H, Shi C, Yang T, Xu B. Electroacupuncture Inhibits the activity of astrocytes in spinal cord in rats with visceral hypersensitivity by inhibiting $\mathrm{p} 2 \mathrm{y} 1$ receptor-mediated MAPK/ERK signaling pathway. Evid Based Complement Alternat Med. 2020;2020:4956179. doi:10.1155/2020/4956179

63. Cho IH, Lee MJ, Jang M, Gwak NG, Lee KY, Jung HS. Minocycline markedly reduces acute visceral nociception via inhibiting neuronal ERK phosphorylation. Mol Pain. 2012;8:13. doi:10.1186/1744-8069-8-13

64. Wang S, Cheng ZY, Chen XJ, Xue HZ. Ulinastatin protects rats with myocardial infarction by activating Nrf2/NOS pathway. Eur Rev Med Pharmacol Sci. 2018;22(24):8990-8998. doi:10.26355/ eurrev_201812_16670

65. Zhang W, Gao J, Zhao T, et al. Proteinase-activated receptor 2 mediates thermal hyperalgesia and is upregulated in a rat model of chronic pancreatitis. Pancreas. 2011;40(2):300-307. doi:10.1097/ MPA.0b013e318201cbc1
66. Colvin LA, Bull F, Hales TG. Perioperative opioid analgesia-when is enough too much? A review of opioid-induced tolerance and hyperalgesia. Lancet. 2019;393(10180):1558-1568. doi:10.1016/ S0140-6736(19)30430-1

67. Lv H, Wei X, Yi X, et al. High-dose ulinastatin to prevent late-onset acute renal failure after orthotopic liver transplantation. Ren Fail. 2020;42(1):137-145. doi:10.1080/0886022X.2020.1717530

68. Wang Z, Tao L, Yan Y, Zhu X. Rationale and design of a prospective, multicentre, randomised, conventional treatment-controlled, parallel-group trial to evaluate the efficacy and safety of ulinastatin in preventing acute respiratory distress syndrome in high-risk patients. BMJ Open. 2019;9(3):e025523. doi:10.1136/bmjopen2018-025523

69. Meng C, Qian Y, Zhang WH, et al. A retrospective study of ulinastatin for the treatment of severe sepsis. Medicine (Baltimore). 2020;99(49):e23361. doi:10.1097/MD.0000000000023361

\section{Publish your work in this journal}

The Journal of Pain Research is an international, peer reviewed, open access, online journal that welcomes laboratory and clinical findings in the fields of pain research and the prevention and management of pain. Original research, reviews, symposium reports, hypothesis formation and commentaries are all considered for publication. The manuscript management system is completely online and includes a very quick and fair peer-review system, which is all easy to use. Visit http:// www.dovepress.com/testimonials.php to read real quotes from published authors. 